\title{
Um manifesto a favor da mídia-educação nas escolas
}

Clara de Melo Araujo

Pontifícia Universidade Católica do Rio de Janeiro (PUC-Rio), Rio de Janeiro/RJ - Brasil

BUCKINGHAM, David. The media education manifesto. Cambridge: Polity Press, 2019.

O livro The media education manifesto de David Buckingham se propõe a trazer uma argumentação convincente sobre a importância da mídia-educação para crianças e jovens, além de apresentar um plano de ação com propostas do que fazer na prática. Buckingham é autor, coautor e editor de mais de 30 livros e, há mais de duas décadas, vem pesquisando sobre a relação das crianças com as mídias na era digital. Atualmente, ele é professor emérito da Loughborough University e professor visitante da Kings College London, ambas na Inglaterra.

Após anos de pesquisas na área, o autor quis fazer um livro articulando as experiências práticas que ele havia vivido com o aporte teórico necessário, construindo um material de referência para educadores, professores e até mesmo políticos. Buckingham deixa claro em diversos momentos do livro que 0 que está escrevendo não é um livro de receitas, ou um passo a passo para ser seguido, mas sim uma proposta de mídia-educação para que cada leitor possa refletir sobre. The media education manifesto é um livro pequeno, de 128 páginas, dividido em uma introdução, nove capítulos curtos e uma conclusão.

$\mathrm{Na}$ introdução do livro, o autor explica que um manifesto deve ter duas funções. A primeira, desenvolvida na primeira metade do livro, seria de convencer o leitor da importância da temática da mídia-educação e, a partir de alguns princípios e objetivos, mostrar que o caminho proposto é possivelmente mais interessante do que os outros que estão sendo realizados ao redor do mundo. A segunda função é realmente fornecer um plano de ação, mostrando de que forma esses objetivos podem ser atingidos no contexto real em que vivemos, tendo como base propostas detalhadas.

Buckingham inicia apresentando um breve panorama do cenário da mídia -educação. Ele aponta que tudo ao nosso redor está mudando rapidamente, desde o final do século XX, principalmente, quando pensamos nas mídias digitais. Os consumidores agora têm mais chances e oportunidades de uso, mas, Revista Educação Online, Rio de Janeiro, n. 34, mai-ago 2020, p. 1-7 
ao mesmo tempo, as grandes empresas estão cada vez coletando e analisando mais dados desses consumidores. Essas grandes empresas, atualmente, formam um monopólio que basicamente controla todas as plataformas e serviços que são oferecidos.

As mídias parecem estar em todas as áreas de nossas vidas, e todos entendem que isso tem lados positivos e também negativos. O problema, segundo Buckingham, é que muitas vezes se vê a mídia-educação como uma simples solução para todos os problemas, ou até mesmo como uma forma de transferir a responsabilidade do Estado para os indivíduos. Outros argumentam que não seria necessária essa educação midiática, uma vez que as crianças e jovens estão tão imersos nessa cultura, que, automaticamente, aprendem as estratégias e os desafios das mídias. Buckingham se posiciona, dizendo que essa não é a visão dele, pois entende que simplesmente saber usar os dispositivos e ferramentas não é o mais importante, e que o empoderamento digital e a visão crítica não chegam de forma espontânea a partir do uso dos equipamentos.

O autor defende que é preciso um programa de mídia-educação coerente, sistemático e contínuo para toda a juventude. Um verdadeiro letramento digital envolve um entendimento crítico e profundo de como as mídias funcionam, o que tem por trás delas e quais são as intenções de quem cria os conteúdos que são oferecidos. Essa é a principal luta de Buckingham, que será abordada em diversos momentos ao longo da leitura.

Após essa introdução, o livro se divide em nove capítulos curtos, os cinco primeiros abordando, de forma mais teórica, qual é a visão de mídia-educação defendida e por que ela seria interessante no contexto em que vivemos. $O$ Capítulo 6 é dedicado a apresentar algumas possíveis armadilhas e problemas que o ensino de mídia pode trazer, alertando para como não deixar que isso aconteça. Finalmente, os três capítulos finais dialogam bastante com a prática e o contexto atual, trazendo as ideias teóricas já desenvolvidas em exemplos realistas e possíveis. Os pontos principais de cada um desses capítulos serão trabalhados a seguir.

O Capítulo 1 é dedicado a apresentar as mudanças que estão ocorrendo no cenário midiático, principalmente, a partir do monopólio de grandes 
empresas. O principal, para o autor, é ter em mente que essas companhias não são apenas empresas de tecnologia, mas também empresas de mídia - elas oferecem para nós meios indispensáveis de comunicação e representação.

Outro ponto importante levantado nesse primeiro capítulo é das continuidades e rupturas das "mídias velhas" para as "mídias novas". Buckingham aponta que existe a tendência de querer separá-las totalmente, mas que isso não é válido, uma vez que, em diversos casos, elas se sobrepõem. Um serviço de streaming de vídeo como a Netflix é uma mídia nova, mas que está distribuindo filmes, que é uma mídia mais antiga, por exemplo. O autor defende que é preciso olhar, sim, para as especificidades de cada mídia, mas também para seus processos de continuidade em uma visão mais global.

No segundo capítulo do livro, Buckingham se propõe a sair da enorme dicotomia de riscos e benefícios que as mídias apresentam, na qual a mídiaeducação seria a solução ideal para potencializar o lado bom enquanto diminui os prejuízos. Buckingham, nesse capítulo, explica, a partir da história, como essa visão dualista pode ser prejudicial e, além de tudo, determinista.

A visão utópica de que a Internet iria, por exemplo, dar poder ao povo para criar seus próprios conteúdos e democratizar a informação é determinista, por achar que tudo isso aconteceria independente da forma e propósito de uso. Essa visão chegou de maneira forte ao campo educacional, principalmente, através da indústria tecnológica que sabe o quão lucrativo esse meio pode ser. Por outro lado, nos últimos anos, cresceram os argumentos que levam em consideração as consequências negativas do uso da tecnologia.

Atualmente, a preocupação com fake news, cyberbullying e "sexting" (mensagens com teor sexual, muitas vezes com as famosas nudes) cresceu, assim como o medo de que a Internet estaria fazendo aumentar os níveis de depressão, autoestima baixa e até mesmo de suicídio entre os jovens. Novamente, Buckingham explica como essas afirmações são muitas vezes deterministas e ingênuas. O autor entende que culpar a tecnologia pelos novos problemas sociais é apontar uma causa simples para um problema complexo. Destaca também que é importante lembrar que existem grandes empresas de segurança on-line, que estão por trás de muitas preocupações alarmantes em torno das mídias. 
O Capítulo 3 foca nos limites do letramento midiático a partir de um olhar histórico das iniciativas que já foram realizadas, principalmente no Reino Unido. Buckingham aponta que existem diferentes concepções desse letramento, de por que ele é necessário e da forma como deve ser feito, muitas vezes algo bastante vago e sem um comprometimento com propostas mais concretas. Com frequência, as iniciativas de mídia-educação caem no dualismo explicado anteriormente e são reduzidas a ensinar a usar as tecnologias de forma segura, como uma forma de autoproteção e autorregulação, para não entrar em contato com os perigos que ela pode oferecer.

Em seu quarto capítulo, Buckingham articula as ideias anteriores, argumentando que, para entendermos de fato a mídia-educação, precisamos ver que ela faz parte de um contexto maior e mais complexo, e não algo que será facilmente resolvido. Para ilustrar, ele usa o exemplo das fake news, que foi a maior preocupação na campanha eleitoral dos EUA de 2016 e que é muito associada com as novas mídias, mas que faz parte de um cenário bem maior. $\mathrm{O}$ autor defende que, muito mais do que simplesmente identificar aquilo que é falso, é preciso reconhecer o viés que está presente em todos os meios de comunicação. Precisamos olhar também o que tem por trás dos acessos gratuitos a sites de comunicação ou entretenimento, que coletam e vendem nossos dados em troca dessa gratuidade. Esse é um exemplo de "plataform capitalism" (algo como "capitalismo das plataformas"), no qual nada é de graça. Todo esse processo é necessário de ser entendido para pensarmos no que há por trás do que vemos e da forma como agimos na Internet.

É no Capítulo 5, que Buckingham explora o que entende por pensamento crítico, de forma sintetizada seria: um processo reflexivo, no qual a gente analisa, sintetiza e avalia as informações a que temos acesso, a partir de questionamentos, da lógica e das evidências. Buckingham então explica que, no Reino Unido, há muitos anos, é usado um conjunto de conceitos críticos para pensar o currículo de mídia-educação. Isso permite que os professores tenham mais autonomia para decidir especificamente o que será trabalhado e também para adequar os temas aos interesses dos alunos e às mudanças da mídia. Esses conceitos críticos, que são desenvolvidos ao longo do capítulo, são: linguagem midiática, representação, produção e audiência. Buckingham aponta 
que foram elencados quando a televisão ainda era predominante, mas que considera que eles ainda são válidos. Nos Capítulos 7 e 8, irá estabelecer a relação de cada um deles com as especificidades das mídias de hoje.

O capítulo 6 nos traz três armadilhas comuns da pedagogia da mídiaeducação. Primeiramente, Buckingham aponta como é fácil cair em uma abordagem protecionista ou defensiva, alertando os jovens sobre os perigos da Internet e visando a que eles se afastem - algo que muitas vezes pode causar o efeito contrário. Outra armadilha é usar a mídia-educação como uma "contrapropaganda", visando a substituir as mensagens falsas que a mídia pode passar por outras ditas mais verdadeiras.

O problema é que, além de depender da relação autoritária em que o professor é o detentor da verdade, os estudantes facilmente começam a simplesmente tentar adivinhar qual é a resposta certa que o professor que ouvir, sem realmente se engajar na questão. A terceira armadilha vai na contramão das duas anteriores, e é a de acreditar que, pelos jovens serem "nativos digitais" e saberem mais do que seus professores, a única coisa que deveria ser feita é dar espaço para eles se expressarem e serem criativos - levando novamente a uma solução rasa do problema.

A abordagem pedagógica em que Buckingham acredita é bastante diferente. Ele identifica três dimensões para a mídia-educação, que vão de encontro com o letramento digital e se articulam entre si. São elas: leitura (análise textual), escrita (produção criativa) e análise contextual (que leva o ambiente social e contextual em consideração, mesmo na leitura e escrita individual). Ao longo do capítulo, ele desenvolve as três dimensões e, ao final, aponta dois princípios-chave para a mídia-educação. O primeiro é começar com aquilo que o estudante já sabe, com seu conhecimento prévio, e o segundo é articular a teoria com a prática, em aulas criativas, mas também analíticas.

Chegamos então aos três capítulos finais do livro, nos quais são apresentadas propostas mais articuladas com a realidade.

No Capítulo 7, Buckingham explora de que forma os conceitos críticos mencionados anteriormente podem se aplicar às mídias sociais. O autor deixa claro que não podemos enxergar as mídias apenas como ferramentas úteis para o dia a dia, mas que elas também devem ser vistas de modo crítico, com suas 
dimensões de representar o mundo, criar significados e gerar lucro. Apenas para ilustrar, é citado, por exemplo, como as fotos que escolhemos para postar em nosso perfil pessoal do Instagram contam uma versão da nossa história, representam algo que queremos mostrar para determinadas pessoas, em um determinado momento. Buckingham não deixa de mencionar novamente a importância de uma perspectiva histórica para a mídia-educação, sem deixar que as novas tecnologias se sobreponham às outras.

O Capítulo 8 tem como título "mídia-educação na prática", e nele vamos ver o autor mostrando como a abordagem que ele propõe pode ser aplicada às fake news e propagandas on-line, ao cyberbullying e discurso de ódio e à autorrepresentação on-line - três tópicos bastante atuais e controversos. Para cada um desses temas, Buckingham articula os conceitos trabalhados ao longo do livro, contextualizando-os histórica e socialmente e trazendo exemplos práticos de atividades e perguntas que podem ser feitas em sala de aula para os alunos. O ponto do autor é que precisamos ter uma visão mais ampla da mídia, principalmente, olhando o contexto da vida social. Ele ressalta que os problemas que enfrentamos on-line, muitas vezes são extensões do que acontece fora na Internet, e que é importante prestarmos atenção nessa continuidade.

No último capítulo do livro, Buckingham irá se direcionar especialmente aos políticos, defendendo a importância de a mídia-educação ser um tópico dos ministros escolares, e não apenas dos agentes reguladores. Novamente, ele irá focar na situação do Reino Unido, dando um panorama histórico do lugar da educação midiática nos currículos escolares. Essa escolha de usar o Reino Unido como exemplo não é apenas por ser o local de residência do autor, mas também por conta de ser a referência mundial quando se trata da mídiaeducação. Buckingham, nesse momento do livro, se posiciona dizendo qual é o lugar que a mídia-educação deveria ocupar nos currículos escolares, apresentando-nos uma proposta bastante pertinente.

Em suas breves páginas de conclusão, Buckingham ressalta a importância de não substituir a regulação da mídia com a educação, pois é necessário reconhecer suas limitações. O autor entende que é essencial que haja responsabilização das empresas privadas, que devem ter regulações mais severas e pagar taxas que serão revertidas em informações culturais e 
treinamento para mídia-educação, por exemplo. Também aponta a necessidade de enxergarmos empresas como Google e Facebook como empresas de mídias e prestarmos mais atenção no uso que fazem de nossos dados. Buckingham conclui o livro, defendendo a importância de a educação ser uma parte de uma estratégia bem mais ampla, mas que nos encoraja a explorar alternativas e a exigir demandas em outros setores.

Esse manifesto da mídia-educação se apresenta como um livro importante de ser lido, não apenas pelos educadores, mas também pelos agentes políticos. Apesar de o foco ser o Reino Unido, o conteúdo que Buckingham traz serve de reflexão também para o nosso país - que tem números crescentes de usuários on-line. Podemos usar o conhecimento e as experiências relatadas no livro, para pensarmos as especificidades do Brasil e também lutarmos pela inserção da mídia-educação em nossos currículos.

Como vimos, não é uma tarefa fácil, e o livro não se propõe a ser um manual de reprodução, mas aponta caminhos e direções interessantes, para que nossas crianças e jovens tenham uma relação mais crítica e saudável com as mídias. 